Voix et Images

voixetimages

\title{
Bibliographie de Gilles Archambault
}

\section{Andréanne Lechasseur-Pierre}

Volume 31, numéro 2 (92), hiver 2006

Gilles Archambault

URI : https://id.erudit.org/iderudit/012879ar

DOI : https://doi.org/10.7202/012879ar

Aller au sommaire du numéro

Éditeur(s)

Université du Québec à Montréal

ISSN

0318-9201 (imprimé)

1705-933X (numérique)

Découvrir la revue

Citer ce document

Lechasseur-Pierre, A. (2006). Bibliographie de Gilles Archambault. Voix et Images, 31(2), 85-104. https://doi.org/10.7202/012879ar d'utilisation que vous pouvez consulter en ligne.

https://apropos.erudit.org/fr/usagers/politique-dutilisation/ 


\title{
B I B L I O GR A P H IE DE G ILLES ARCHAMB A U LT
}

\author{
$+++$ \\ ANDRÉANNE LECHASSEUR-PIERRE \\ Université Concordia
}

\section{EUVRES}

\section{I.1. Romans}

+ Une suprême discrétion, Montréal, Le Cercle du Livre de France, 1963, 158 p.

+ La vie à trois, Montréal, Le Cercle du Livre de France, 1965, 178 p. ; Montréal, Stanké, coll. «10/10», 1981, 183 p. ; Montréal, Boréal, coll. «Boréal Compact», 2004, 194 p.

+ Le tendre matin, Montréal, Le Cercle du Livre de France, 1969, 146 p. ; Montréal, Boréal, 1994, $155 \mathrm{p}$.

+ Parlons de moi. Récit complaisant, itératif, contradictoire et pathétique d'une autodestruction, Montréal, Le Cercle du Livre de France, 1970, 204 p. ; Montréal, Stanké, coll. «10/10», 1980, 211 p. ; Montréal, Boréal, coll. «Boréal Compact», 1997, 164 p.

+ La fleur aux dents, Montréal, Le Cercle du Livre de France, 1971, 238 p. ; Montréal, Les Quinze, 1980, 247 p. ; Montréal, Boréal, coll. «Boréal Compact», 2002, 184 p.

+ La fuite immobile, Montréal, L'Actuelle, 1974, 170 p. ; Montréal, Stanké, 1982, coll. «10/10», 180 p. ; Montréal, Boréal, coll. «Boréal Compact», 2000, 175 p.

+ Les pins parasols, Montréal, Les Quinze, 1976, 158 p. ; Montréal, Les Quinze, 1980, 164 p. ; Montréal, l'Hexagone, 1988, 153 p. ; Montréal, Boréal, coll. «Boréal Compact», 2003, 178 p.

+ Le voyageur distrait, Montréal, Stanké, 1981, 120 p. ; Montréal, l'Hexagone, 1988, 147 p.

+ À voix basse, Montréal, Boréal express, 1983, 157 p.

+ Premiers amours, Montréal, Stanké, 1988, 261 p.

+ Les choses d'un jour, Montréal, Boréal, 1991, 148 p.

+ Un homme plein d'enfance, Montréal, Boréal, 1996, 126 p.

+ Les maladresses du cœur, Montréal, Boréal, 1998, 221 p.

+ Courir à sa perte, Montréal, Boréal, 2000, 198 p.

+ De l'autre côté du pont, Montréal, Boréal, 2004, 196 p.

\section{I.2. Récits}

+ Stupeur, Montréal, Du Sentier, 1979, 77 p. ; Montréal, l'Hexagone, 1994, 70 p.

+ Un après-midi de septembre, Montréal, Boréal, coll. «Boréal Compact», 1993, 109 p. 


\section{I.3. Recueils de nouvelles}

+ Enfances lointaines, Montréal, Le Cercle du Livre de France, 1972, 120 p. ; Montréal, Boréal, 1992, $99 \mathrm{p}$.

+ L'obsédante obèse et autres agressions, Montréal, Boréal, 1987, 145 p.; Montréal, Boréal, coll. «Boréal Compact», 1996, 145 p.

+ Tu ne me dis jamais que je suis belle, Montréal, Boréal, 1994, 155 p. ; Montréal, Boréal, coll. «Boréal Compact», 1996, 155 p.

+ Comme une panthère noire, Montréal, Boréal, 2001, 208 p.

+ De si douces dérives, Montréal, Boréal, 2003, 165 p.

\section{I.4. Texte dramatique}

+ Le tricycle, suivi de Bud Cole Blues, Montréal, Leméac, 1974, 79 p.

\section{I.5. Chroniques et essais}

+ Une discothèque de base (avec Pyer Gingras et Jacques Thériault), Montréal, Leméac, 1973, $242 \mathrm{p}$.

+ Les plaisirs de la mélancolie, Montréal, Les Quinze, 1980, 133 p. ; Montréal, Boréal, coll. «Papiers collés», 1994, 116 p.

+ Le regard oblique. Rumeurs de la vie littéraire, Montréal, Boréal, coll. «Papiers collés», 1984, $179 \mathrm{p}$.

+ Chroniques matinales, Montréal, Boréal, coll. «Papiers collés», 1989, 177 p.

+ Nouvelles chroniques matinales, Montréal, Boréal, coll. «Papiers collés», 1994, 169 p.

+ Dernières chroniques matinales, Montréal, Boréal, coll. «Papiers collés», 1996, 163 p.

\section{I.6. Textes de collectifs ou de revues}

+ «Le tricycle», Liberté, n 69, septembre-décembre 1970, p. 41-60.

+ «Quarante moins trois», Liberté, no 73, mai 1971, p. 24-27.

+ «La radio, un métier trop captivant!», Le Jour, 28 septembre 1974, p. 22.

+ «Les "presses universitaires", qu'ossa donne?», Les Livres d'ici, n 42, 1976, p. 10.

+ "Mon très beau nombril», Liberté, n 111, mai-juin 1977, p. 13-17.

+ «Prenez le tour du Québec (les tournées)", Liberté, n 134, mars-avril 1981, p. 74-78.

+ «Moi, David, toi Goliath!», Les Livres d'ici, 21 octobre 1981, p. 1 et 4.

+ «À voix basse», Liberté, nº 144, décembre 1982, p. 22-32.

+ «Les confidences muettes», Liberté, n 145 , février 1983, p. 8-10.

+ «La note bleue», Liberté, $\mathrm{n}^{\circ} 155$, octobre 1984, p. 64-67.

+ «Le rose et le vert», Liberté, n 156 , décembre 1984, p. 107-108.

+ «Pour les contemplatifs», Liberté, n 157, février 1985, p. 127-129.

+ «Le maître écrit-il? », Liberté, no 159, juin 1985, p. 77-78.

+ «Nécrologie», Liberté, n 160, août 1985, p. 119-120.

+ «Dieu lui-même...", Liberté, no 161, octobre 1985, p. 134-135.

+ "Vive et tourisme», Liberté, no 162 , décembre 1985, p. 104-105.

+ «Amour maternel», Gilles Archambault et al., Fuites \& poursuites, Montréal, Les Quinze, coll. «10/10», 1985, p. 37-49.

+ «Claude Mathieu, écrivain», Lettres québécoises, n 40, hiver 1985-1986, p. 9-10.

+ «Un ami», Liberté, no 164, avril 1986, p. 92-93.

+ «Témoignage», Les Écrits du Canada français, n 57, 1986, p. 1-224. 
+ «L'insondable», Liberté, n 173, octobre 1987, p. 8-12.

+ «Naissance», Nouvelles de la francophonie. Belgique, Congo, France, Maroc, Martinique, Louisiane/Québec, L'âge d'homme/L'instant même, coll. «L'atelier imaginaire», 1987, p. 17-22.

+ «La radio comme un livre», Les Écrits du Canada français, n 64, 1988, p. 43-47.

+ «Puisqu'il faut naître quelque part...», Louise Dupré, Bruno Roy et France Théoret (dir.), Montréal des écrivains, Montréal, l'Hexagone, coll. «Typo», 1988, p. 9-12.

+ «Un cinéphile d'occasion», Liberté, no 185, octobre 1989, p. 31-35.

+ «Gilles Archambault», Louise Maheux-Forcier et Jean-Guy Pilon (dir.), L'écrivain et la musique (communications de la XXI rencontre québécoise internationale des écrivains tenue à Ste-Adèle \& Montréal, du 20 au 24 avril 1993), Montréal, l'Hexagone, 1994, p. 31-35.

+ «Robert Charbonneau ou l'écrivain empêché», Les Écrits du Canada français, n 83, avril 1995, p. 61-68.

+ «Journal en mars», Les Écrits du Canada français, no 87, août 1996, p. 103-118.

+ «La ville», Liberté, n 244 , août 1999, p. 112-114.

+ «J'avoue, je n’ai jamais lu Ulysse», Nuit blanche, no 87, été 2002, p. 6-7.

+ «Héros de papiers », Marc Robitaille (dir.), Une enfance bleu-blanc-rouge, Montréal, Les 400 Coups, 2000, p. 43-46.

\section{I.7. Textes journalistiques}

+ «Humiliés et offensés», La Presse, 9 janvier 1971, p. C3.

+ "L'écriture, cette maladie honteuse», Le Devoir, 15 décembre 1973, p. 17.

+ «Éloge de l'emmerdement», Voir, vol. 6, n 5, 3 janvier 1992, p. 25.

+ «Quand le facteur s'envole», Voir, vol. 6, n 6, 9 janvier 1992, p. 29.

+ «Un roman à mâcher», Voir, vol. 6, nº 7, 16 janvier 1992, p. 31.

+ «La voix du village», Voir, vol. 6, n 8, 23 janvier 1992, p. 30.

+ «Les colonnes sont indispensables», Voir, vol. 6, n 9, 30 janvier 1992, p. 35.

+ «Un objectif à atteindre», Voir, vol. 6, n 10, 6 février 1992, p. 38.

+ «La cour est presque ouverte», Voir, vol. 6, no 12, 20 février 1992, p. 38.

+ «Motard un jour...», Voir, vol. 6, nº 13, 27 février 1992, p. 42.

+ «La neuvième avec pastilles», Voir, vol. 6, nº 14, 5 mars 1992, p. 42.

+ «Le bel aujourd'hui», Voir, vol. 6, nº 15, 12 mars 1992, p. 42.

+ «Petit rappel», Voir, vol. 6, n 16, 19 mars 1992, p. 42.

+ «Pitié pour les voyageurs», Voir, vol. 6, n 17, 26 mars 1992, p. 42.

+ «Les fesses impies», Voir, vol. 6, n 18, 2 avril 1992, p. 41.

+ «Le goût du désastre», Voir, vol. 6, n 20, 16 avril 1992, p. 46.

+ «L'invitation au sommeil», Voir, vol. 6, n 21, 23 avril 1992, p. 46.

+ «Le transport des huîtres", Voir, vol. 6, n 22, 30 avril 1992, p. 42.

+ «Nature très morte», Voir, vol. 6, n 23, 7 mai 1992, p. 46.

+ «Le swing du Seigneur», Voir, vol. 6, n 24, 14 mai 1992, p. 46.

+ «Où est passé ce chien?», Voir, vol. 6, n 25, 21 mai 1992, p. 45.

+ «Bonheur à ceux par qui le scandale arrive», Voir, vol. 6, n 26, 28 mai 1992, p. 45.

+ "Regrets inutiles», Voir, vol. 6, n 27, 4 juin 1992, p. 52.

+ «Écrire comme on respire», Voir, vol. 6, n 28, 11 juin 1992, p. 56.

+ «Une journée dans le monde», Voir, vol. 6, n 29, 18 juin 1992, p. 61.

+ «Le petit homme qui va au cimetière», Le Devoir, 26 septembre 1992, p. D4.

+ «Les dangers de la lecture», Le Devoir, 3 octobre 1992, p. D4. 
+ "Bonsoir, les choses d'ici-bas», Le Devoir, 10 octobre 1992, p. D4.

+ «Une histoire de cœur», Le Devoir, 24 octobre 1992, p. D4.

+ «Beau comme la mort», Le Devoir, 7 novembre 1992, p. D25.

+ «Lueurs de bonheur», Le Devoir, 14 novembre 1992, p. D6.

+ «Fin de vie», Le Devoir, 21 novembre 1992, p. D4.

+ «Misanthrope à l'anglaise», Le Devoir, 5 décembre 1992, p. D4.

+ «Mourir de désespoir», Le Devoir, 19 décembre 1992, p. D12.

+ «Une totale désespérance», Le Devoir, 31 décembre 1992, p. B8.

+ «Refuge en forêt», Le Devoir, 9 janvier 1993, p. C6.

+ «Roman avec personnages», Le Devoir, 23 janvier 1993, p. C22.

+ «Ā Londres sous la pluie», Le Devoir, 30 janvier 1993, p. D3.

+ «Sur fond de neige», Le Devoir, 6 février 1993, p. D4.

+ «De quelques fureurs», Le Devoir, 20 février 1993, p. D4.

+ «Montréal au loin», Le Devoir, 6 mars 1993, p. D4.

+ "L'intimité d'une voix», Le Devoir, 13 mars 1993, p. D4.

+ «À l'ombre de Baudelaire», Le Devoir, 20 mars 1993, p. D4.

+ «Une violence indue», Le Devoir, 27 mars 1993, p. D4.

+ «Une mauvaise éducation», Le Devoir, 3 avril 1993, p. D4.

+ «Éloge de la chronique», Le Devoir, 10 avril 1993, p. D9.

+ «Cruelles faiblesses», Le Devoir, 17 avril 1993, p. D4.

+ "Avec pudeur et impudence», Le Devoir, $1^{\mathrm{er}}$ mai 1993, p. D4.

+ "Ce qui nous manque», Le Devoir, 3 mai 1993, p. D4.

+ «Mystique et lyrique», Le Devoir, 15 mai 1993, p. D4.

+ «Heureux divertissement», Le Devoir, 22 mai 1993, p. D4.

+ "Humeurs nostalgiques», Le Devoir, 5 juin 1993, p. D4.

+ "C'était hier», Le Devoir, 12 juin 1993, p. D6.

+ «Savoir refuser», Le Devoir, 19 juin 1993, p. D8.

+ «Lecture de jazz. Comment se préparer à la catastrophe pour le Festival», Le Devoir, 19 juin 1993, p. D4.

+ «Rendez-vous de juillet», Le Devoir, 2 juillet 1993, p. A3.

+ «Canada jazz day", Le Devoir, 3 juillet 1993, p. A3.

+ «Le plaisir d'être là», Le Devoir, 5 juillet 1993, p. A3.

+ «Debout! Valeureux!», Le Devoir, 6 juillet 1993, p. A3.

+ «Il y a plusieurs festivals», Le Devoir, 7 juillet 1993, p. A3.

+ «Le droit à l'erreur», Le Devoir, 8 juillet 1993, p. A3.

+ «Blues des lendemains», Le Devoir, 9 juillet 1993, p. A3.

+ «Vu du neuvième», Le Devoir, 10 juillet 1993, p. A3.

+ "Entre le risque et les options sûres», Le Devoir, 12 juillet 1993, p. A1.

+ "Amours champêtres", Le Devoir, 18 septembre 1993, p. D5.

+ «Pour l'amour d'une vache», Le Devoir, 25 septembre 1993, p. D4.

+ «Misogynie à part», Le Devoir, 2 octobre 1993, p. D3.

+ «Un monde d'émotion», Le Devoir, 9 octobre 1993, p. D3.

+ «Notes sur le vif», Le Devoir, 16 octobre 1993, p. D3.

+ «Merveilleux Diderot», Le Devoir, 23 octobre 1993, p. D3.

+ «Sénèque notre contemporain», Le Devoir, 30 octobre 1993, p. D2.

+ «Ultime décision», Le Devoir, 6 novembre 1993, p. D7. 
+ «Un diable classique», Le Devoir, 13 novembre 1993, p. D4.

+ «Des civils bien inquiétants», Le Devoir, 20 novembre 1993, p. D4.

+ «La vie à l'indienne», Le Devoir, 27 novembre 1993, p. D5.

+ «Humeurs balzaciennes», Le Devoir, 4 décembre 1993, p. D4.

+ «Les plaisirs de la bibliographie», Le Devoir, 11 décembre 1993, p. D2.

+ "Vous lisez Sainte-Beuve?", Le Devoir, 18 décembre 1993, p. D3.

+ «L'honneur de la prose», Le Devoir, 24 décembre 1993, p. C11.

+ «Fréquentations transatlantiques», Le Devoir, 29 janvier 1994, p. D3.

+ «Tout ramener à soi», Le Devoir, 5 février 1994, p. D3.

+ «Les dangers du cinématographe», Le Devoir, 12 février 1994, p. D3.

+ «Clochardises», Le Devoir, 19 février 1994, p. D5.

+ "Chef-d'œuvre retrouvé», Le Devoir, 26 février 1994, p. D4.

+ "Ambitions déçues", Le Devoir, 5 mars 1994, p. D5.

+ "L’homme qui ne riait pas», Le Devoir, 12 mars 1994, p. D4.

+ «La douleur d'aimer», Le Devoir, 19 mars 1994, p. D3.

+ «Le roman du doute», Le Devoir, 26 mars 1994, p. D3.

+ «Dire sa vie», Le Devoir, 2 avril 1994, p. D3.

+ «De quelques petites terreurs», Le Devoir, 9 avril 1994, p. D3.

+ "À la terre comme à la terre", Le Devoir, 16 avril 1994, p. D2.

+ «Inquiets comme à seize ans», Le Devoir, 23 avril 1994, p. D8.

+ «Chroniques d'une époque révolue», Le Devoir, 30 avril 1994, p. D6.

+ «Rumeurs italiennes», Le Devoir, 7 mai 1994, p. D3.

+ "Aveux incongrus», Le Devoir, 14 mai 1994, p. D5.

+ «Tours du monde», Le Devoir, 21 mai 1994, p. D2.

+ «Du danger des honneurs», Le Devoir, 28 mai 1994, p. D4.

+ «Bienveillante utopie», Le Devoir, 4 juin 1994, p. D3.

+ «Les aiguilles du temps», Le Devoir, 11 juin 1994, p. D6.

+ «Les affres du moi», Le Devoir, 18 juin 1994, p. D3.

+ "Charles Lloyd... le retour», Le Devoir, 30 juin 1994, p. B11.

+ «David Murray, jazzman époustouflant», Le Devoir, 2 juillet 1994, p. A3.

+ «Ron Carter ou l'accompagnateur», Le Devoir, 4 juillet 1994, p. B8.

+ «Mal Waldron ou l'obstination», Le Devoir, 6 juillet 1994, p. B8.

+ «Ernestine Anderson ou une sorte de blues», Le Devoir, 6 juillet 1994, p. B8.

+ «J. J. Johnson ou la troublante perfection», Le Devoir, 8 juillet 1994, p. B9.

+ «Paul Bley ou la séduction du silence», Le Devoir, 9 juillet 1994, p. A3.

+ «À la fortune du mot», Le Devoir, 10 septembre 1994, p. D9.

+ «Un vagabond perpétuel», Le Devoir, 17 septembre 1994, p. D7.

+ «Un secret bien gardé», Le Devoir, 24 septembre 1994, p. D3.

+ «Des voyages fort exotiques», Le Devoir, $1^{\text {er }}$ octobre 1994, p. D2.

+ "Chroniques municipales», Le Devoir, 8 octobre 1994, p. D2.

+ «Le petit homme du cimetière», Le Devoir, 15 octobre 1994, p. D3.

+ "Les plaisirs du vieil âge», Le Devoir, 22 octobre 1994, p. D2.

+ «Au pays de l'esclavage», Le Devoir, 29 octobre 1994, p. D2.

+ «Diderot, fils de personne», Le Devoir, 5 novembre 1994, p. D6.

+ «Un roman plus noir que noir», Le Devoir, 12 novembre 1994, p. D9.

+ «Rien qu'une fable», Le Devoir, 19 novembre 1994, p. D10. 
+ «Ultime solitude», Le Devoir, 26 novembre 1994, p. D4.

+ «Darien ou l'anarchie», Le Devoir, 3 décembre 1994, p. D6.

+ «Le livre de l'hallucination», Le Devoir, 10 décembre 1994, p. D13.

+ «Un antidote contre les petites misères», Le Devoir, 17 décembre 1994, p. D6.

+ «Incitation à la lecture», Le Devoir, 17 décembre 1994, p. D4.

+ «Un vade-mecum pour curieux», Le Devoir, 10 janvier 1995, p. B9.

+ "Au bout du tunnel», Le Devoir, 14 janvier 1995, p. C8.

+ «Écrivains de charme», Le Devoir, 21 janvier 1995, p. C17.

+ «Les malheurs de l'amour», Le Devoir, 28 janvier 1995, p. C10.

+ «Écrire pour voir», Le Devoir, 4 février 1995, p. D7.

+ «De la fragilité du couple», Le Devoir, 11 février 1995, p. D4.

+ "Deux récits de Mérimée», Le Devoir, 18 février 1995, p. D6.

+ «L'amour et ce qui s'ensuit», Le Devoir, 4 mars 1995, p. D2.

+ «Des nouvelles du grand frère», Le Devoir, 11 mars 1995, p. D4.

+ "Fréquentations voltairiennes», Le Devoir, 18 mars 1995, p. D4.

+ «Pour un jeune centenaire», Le Devoir, 25 mars 1995, p. D3.

+ «On ne vit qu'une fois», Le Devoir, 1 ${ }^{\mathrm{er}}$ avril 1995, p. D3.

+ "Mais où est donc Donna?», Le Devoir, 8 avril 1995, p. D5.

+ "Chroniques de l'éphémère», Le Devoir, 15 avril 1995, p. D2.

+ «Du hasard d'être né», Le Devoir, 22 avril 1995, p. D5.

+ «Narrateur malgré lui», Le Devoir, 29 avril 1995, p. D2.

+ "Vison de rêve», Le Devoir, 6 mai 1995, p. D3.

+ "Les chasseurs de papillons», Le Devoir, 13 mai 1995, p. D4.

+ «Pour la radio», Le Devoir, 16 mai 1995, p. A6.

+ "Vanité ultime», Le Devoir, 20 mai 1995, p. D4.

+ «Rumeur d'enfance», Le Devoir, 27 mai 1995, p. D2.

+ «Denrées périssables», Le Devoir, 3 juin 1995, p. D2.

+ "Bavard et drôle», Le Devoir, 10 juin 1995, p. D3.

+ "Un début dans la vie», Le Devoir, 17 juin 1995, p. D5.

+ "David Murray ou l'ardeur», Le Devoir, 29 juin 1995, p. B8.

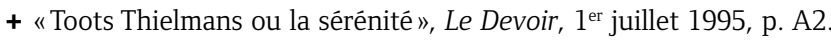

+ «Javon Jackson ou l'héritier», Le Devoir, 4 juillet 1995, p. B8.

+ «Randy Weston ou le riche héritier», Le Devoir, 5 juillet 1995, p. B8.

+ «Sonny Simmons ou le retour», Le Devoir, 6 juillet 1995, p. B8.

+ «Dave Holland ou le brio», Le Devoir, 7 juillet 1995, p. B9.

+ "Henry Theadgill ou l'exigence», Le Devoir, 8 juillet 1995, p. A2.

+ "Descente aux enfers», Le Devoir, 2 septembre 1995, p. D4.

+ «Les délices de l'âge ingrat», Le Devoir, 9 septembre 1995, p. D3.

+ «Un début à tout», Le Devoir, 16 septembre 1995, p. D6.

+ «Enfermements», Le Devoir, 23 septembre 1995, p. D4.

+ "Amour et esthétisme», Le Devoir, 30 septembre 1995, p. D5.

+ "Avec humour et tendresse», Le Devoir, 7 octobre 1995, p. D5.

+ «La pauvreté des uns», Le Devoir, 14 octobre 1995, p. D7.

+ «Un bien étrange Kafka», Le Devoir, 21 octobre 1995, p. D5.

+ "La chaire est très triste», Le Devoir, 28 octobre 1995, p. D5.

+ «Le goût de lire la sublime commère», Le Devoir, 4 novembre 1995, p. D4. 
+ "L'attirance de la mort», Le Devoir, 11 novembre 1995, p. D8.

+ «Un petit livre qui parle au cœur», Le Devoir, 18 novembre 1995, p. D9.

+ «La vie est drôle», Le Devoir, 25 novembre 1995, p. D5.

+ «Invraisemblable mais vrai», Le Devoir, 2 décembre 1995, p. D4.

+ "Amants, heureux amants», Le Devoir, 9 décembre 1995, p. D2.

+ "Une descente aux enfers», Le Devoir, 16 décembre 1995, p. D4.

+ «Le temps de la certitude», Le Devoir, 23 décembre 1995, p. D5.

+ «Éloge du moment présent», Le Devoir, 3 février 1996, p. D4.

+ «Au plaisir du dilettante», Le Devoir, 10 février 1996, p. D6.

+ «Que c'est laid, la vie!», Le Devoir, 10 février 1996, p. D4.

+ «Retour au pays natal», Le Devoir, 24 février 1996, p. D3.

+ «Raconter une histoire», Le Devoir, 2 mars 1996, p. D7.

+ «Un classique bien inquiétant», Le Devoir, 9 mars 1996, p. D6.

+ «Fantasme», Le Devoir, 16 mars 1996, p. D7.

+ «L'art pour l'art», Le Devoir, 23 mars 1996, p. D13.

+ «Partir c'est vivre un peu», Le Devoir, 30 mars 1996, p. D7.

+ «Lire n'est pas un pensum», Le Devoir, 6 avril 1996, p. D3.

+ «Des confessions, vraiment?», Le Devoir, 13 avril 1996, p. D3.

+ "Sans effet de littérature», Le Devoir, 27 avril 1996, p. D6.

+ «La voie amoureuse», Le Devoir, 4 mai 1996, p. D6.

+ "L'être et le paraître», Le Devoir, 4 mai 1996, p. D5.

+ «Les classiques modernes à jamais», Le Devoir, 18 mai 1996, p. D4.

+ «Un grand intellectuel», Le Devoir, 1 ${ }^{\mathrm{er}}$ juin 1996, p. D3.

+ «Imprévisible Faulkner», Le Devoir, 8 juin 1996, p. D12.

+ «Un amour comme le nôtre», Le Devoir, 15 juin 1996, p. D9.

+ «Phil Wood ou la maîtrise», Le Devoir, 27 juin 1996, p. B8.

+ « Jim Hall ou la finesse», Le Devoir, 29 juin 1996, p. B3.

+ «James Moody ou la fidélité», Le Devoir, 6 juillet 1996, p. B3.

+ «Sonny Rollins ou le gigantisme», Le Devoir, 15 juillet 1996, p. B9.

+ «Ces livres qu'on aime», Le Devoir, 7 septembre 1996, p. D14.

+ «Des puritains bien inquiétants», Le Devoir, 14 septembre 1996, p. D7.

+ «Plaisir à Calet», Le Devoir, 21 septembre 1996, p. D8.

+ "Tchékhov, l'insaisissable», Le Devoir, 28 septembre 1996, p. D5.

+ «Une disparition dans la blancheur», Le Devoir, 5 octobre 1996, p. D5.

+ «Portraits en tous genres», Le Devoir, 12 octobre 1996, p. D7.

+ "Histoire d'être», Le Devoir, 19 octobre 1996, p. D8.

+ «Est-ce ainsi », Le Devoir, 26 octobre 1996, p. D6.

+ «Un écrivain multiple», Le Devoir, 2 novembre 1996, p. D6.

+ "L'amour comme torture», Le Devoir, 9 novembre 1996, p. D23.

+ «Parmi tant d'autres», Le Devoir, 16 novembre 1996, p. D9.

+ «La blessure de vivre», Le Devoir, 23 novembre 1996, p. D9.

+ "Plaisirs de collectionneurs», Le Devoir, 30 novembre 1996, p. D9.

+ «Plaisirs de dames», Le Devoir, 7 décembre 1996, p. D9.

+ «Diables et revenants», Le Devoir, 14 décembre 1996, p. D14.

+ «Relire Balzac», Le Devoir, 28 décembre 1996, p. D6.

+ «Le plaisir de dire non», Le Devoir, 11 janvier 1997, p. D4. 
+ «Personnages en quête d'auteur», Le Devoir, 18 janvier 1997, p. D4.

+ «Roman du souvenir», Le Devoir, 25 janvier 1997, p. D4.

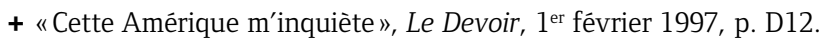

+ «S'écrire soi-même», Le Devoir, 8 février 1997, p. D4.

+ «Dans le meilleur des mondes», Le Devoir, 15 février 1997, p. D4.

+ «Un début dans la vie», Le Devoir, 22 février 1997, p. D6.

+ "Climats en tout genre», Le Devoir, $1^{\text {er }}$ mars 1997, p. D6.

+ «Du côté de chez Candide», Le Devoir, 8 mars 1997, p. D4.

+ «Redécouvrir Alphonse Daudet», Le Devoir, 15 mars 1997, p. D11.

+ «Une philosophie laïque», Le Devoir, 22 mars 1997, p. D6.

+ «Blonblon, Lucette et Renée la blonde», Le Devoir, 29 mars 1997, p. D7.

+ "Stendhal en mineur», Le Devoir, 5 avril 1997, p. D8.

+ "Pour que jeunesse se passe, ou se vive», Le Devoir, 12 avril 1997, p. D6.

+ «Sœurs de Shakespeare», Le Devoir, 19 avril 1997, p. D8.

+ «Un témoin du siècle», Le Devoir, 26 avril 1997, p. D7.

+ «Les exigences de l'amour», Le Devoir, 3 mai 1997, p. D6.

+ «Je vous écris aujourd'hui», Le Devoir, 10 mai 1997, p. D9.

+ «Le chemin d'un écrivain», Le Devoir, 17 mai 1997, p. D9.

+ «Séjour dans l'honneur», Le Devoir, 24 mai 1997, p. D7.

+ «Pauvre Jack!», Le Devoir, 31 mai 1997, p. D2.

+ «Le plus heureux des hommes», Le Devoir, 7 juin 1997, p. D5.

+ «Trop en faire», Le Devoir, 14 juin 1997, p. D12.

+ «Père et mère, tu supporteras», Le Devoir, 21 juin 1997, p. D12.

+ «Festivals en tout genre», Le Devoir, 26 juin 1997, p. A8.

+ «Ventres mous», Le Devoir, 3 juillet 1997, p. A6.

+ «Le don de la langue», Le Devoir, 10 juillet 1997, p. A6.

+ "Affaire de cousinage», Le Devoir, 17 juillet 1997, p. A6.

+ «Au sujet de l'emmenthal», Le Devoir, 24 juillet 1997, p. A6.

+ «Médiocrité», Le Devoir, 31 juillet 1997, p. A6.

+ «Montree-al Canada», Le Devoir, 7 août 1997, p. A6.

+ «Dictionnaire des idées reçues (édition québécoise)», Le Devoir, 14 août 1997, p. A6.

+ «Êtes-vous élitiste?», Le Devoir, 21 août 1997, p. A6.

+ «Pourquoi je ne serai pas candidat à la mairie», Le Devoir, 27 août 1997, p. A6.

+ «L'été se termine, allons au cinéma!», Le Devoir, 5 septembre 1997, p. A8.

+ «Le roi, la reine et son petit prince», Le Devoir, 12 septembre 1997, p. A8.

+ «Pas vrai! Tu n'es pas nationaliste!», Le Devoir, 19 septembre 1997, p. A10.

+ «Mes livres au programme?», Le Devoir, 26 septembre 1997, p. A10.

+ «Embarquement immédiat», Le Devoir, 3 octobre 1997, p. A10.

+ «Une télévision vraiment autre», Le Devoir, 10 octobre 1997, p. A12.

+ «L'irrésistible appel de la médiocrité», Le Devoir, 17 octobre 1997, p. A12.

+ «Brouillon de culture», Le Devoir, 24 octobre 1997, p. A10.

+ "Pas demain la veille», Le Devoir, 31 octobre 1997, p. A10.

+ «Pas Louis-Ferdinand, l'autre», Le Devoir, 7 novembre 1997, p. A8.

+ «Pour un petit coquelicot», Le Devoir, 14 novembre 1997, p. A12.

+ "Vous écrivez des livres?", Le Devoir, 21 novembre 1997, p. A10.

+ «Mes insolubles angoisses», Le Devoir, 28 novembre 1997, p. A10. 
+ «Un enfant de la balle», Le Devoir, 5 décembre 1997, p. A10.

+ «Sept fois sa langue», Le Devoir, 12 décembre 1997, p. A12.

+ «Et si nous changions les masques», Le Devoir, 19 décembre 1997, p. A10.

+ "Bibliothèques, petites et grandes», Le Devoir, 16 janvier 1998, p. A10.

+ «Un piéton de Montréal», Le Devoir, 23 janvier 1998, p. A10.

+ «Être journaliste», Le Devoir, 30 janvier 1998, p. A10.

+ «L'art d'exploiter», Le Devoir, 6 février 1998, p. A10.

+ "Si j'étais malade», Le Devoir, 13 février 1998, p. A10.

+ «Des drapeaux par milliers», Le Devoir, 20 février 1998, p. A10.

+ «Transport public», Le Devoir, 27 février 1998, p. A8.

+ «On connaît la chanson», Le Devoir, 6 mars 1998, p. A8.

+ «Droit de parole», Le Devoir, 13 mars 1998, p. A10.

+ «Figures charismatiques», Le Devoir, 20 mars 1998, p. A10.

+ «Sale printemps», Le Devoir, 27 mars 1998, p. A10.

+ «Être et paraître», Le Devoir, 3 avril 1998, p. A10.

+ «Les Québécois ne lisent pas», Le Devoir, 10 avril 1998, p. A10.

+ «Peut-être impur, mais sûrement mou», Le Devoir, 24 avril 1998, p. A10.

+ «Décence zéro», Le Devoir, $1^{\mathrm{er}}$ mai 1998, p. A10.

+ «Je t'aime Ariane», Le Devoir, 8 mai 1998, p. A12.

+ «Liberté de presse», Le Devoir, 15 mai 1998, p. A10.

+ "Attention, je recule fréquemment», Le Devoir, 22 mai 1998, p. A10.

+ «Les dangers du voyage», Le Devoir, 29 mai 1998, p. A10.

+ «Je serais donc un intellectuel», Le Devoir, 5 juin 1998, p. A10.

+ «L'appel du grand large», Le Devoir, 12 juin 1998, p. A10.

+ «On a un nouveau premier ministre», Le Devoir, 19 juin 1998, p. A12.

+ «Le blues des invendus», Le Devoir, 26 juin 1998, p. A8.

+ "C'est pas de la tarte», Le Devoir, 3 juillet 1998, p. A8.

+ «Comme une lettre à la poste», Le Devoir, 10 juillet 1998, p. A8.

+ "Le mûr des pâmoisons", Le Devoir, 17 juillet 1998, p. A10.

+ "Quand la devise est faible», Le Devoir, 24 juillet 1998, p. A8.

+ «Buffet chaud et froid», Le Devoir, 31 juillet 1998, p. A8.

+ «Vraiment juste pour rire?», Le Devoir, 7 août 1998, p. A8.

+ "Petites et grandes médiocrités», Le Devoir, 14 août 1998, p. A10.

+ «Occupations estivales», Le Devoir, 21 août 1998, p. A10.

+ «Loin de la Cour suprême», Le Devoir, 28 août 1998, p. A10.

+ «Justifications», Le Devoir, 4 septembre 1998, p. A10.

+ "La très grande noirceur», Le Devoir, 11 septembre 1998, p. A10.

+ «Le devoir d'indignation», Le Devoir, 14 septembre 1998, p. A6.

+ "Une toute petite chose, vraiment», Le Devoir, 21 septembre 1998, p. A6.

+ "On n'est jamais si bien servi...», Le Devoir, 28 septembre 1998, p. A6.

+ «Il est parfois gênant d'être un homme», Le Devoir, 5 octobre 1998, p. A6.

+ "Être de son temps», Le Devoir, 13 octobre 1998, p. A8.

+ «Un dîner de cons», Le Devoir, 19 octobre 1998, p. A8.

+ «L'attrait du vide», Le Devoir, 26 octobre 1998, p. A6.

+ «Ils lancent et ils comptent», Le Devoir, 2 novembre 1998, p. A8.

+ «Revue de presse», Le Devoir, 9 novembre 1998, p. A10. 
+ «L'effet Charest», Le Devoir, 16 novembre 1998, p. A9.

+ «Une certaine gêne», Le Devoir, 23 novembre 1998, p. A9.

+ «Paris en mars», Le Devoir, 7 décembre 1998, p. A7.

+ «La fierté, tu parles!», Le Devoir, 14 décembre 1998, p. A7.

+ «Le calendrier de Lucienne», Le Devoir, 21 décembre 1998, p. A7.

+ «Ottawa, le bus, le parfum et le cousin», Le Devoir, 28 décembre 1998, p. A7.

+ «Revues de fin d'année», Le Devoir, 4 janvier 1999, p. A7.

+ «Elles valent mille mots», Le Devoir, 11 janvier 1999, p. A7.

+ «Une responsabilité historique», Le Devoir, 18 janvier 1999, p. A7.

+ «Le bras canadien», Le Devoir, 25 janvier 1999, p. A7.

+ «Parlez-moi d'argent», Le Devoir, 1 1er février 1999, p. A7.

+ "Avons-nous une gueule d'atmosphère?», Le Devoir, 8 février 1999, p. A7.

+ «J'aime Yvon Deschamps», Le Devoir, 15 février 1999, p. A7.

+ «Citoyens de quel monde?», Le Devoir, 22 février 1999, p. A7.

+ «M'as-tu vu?", Le Devoir, ${ }^{\text {er }}$ mars 1999, p. A7.

+ "Ici et ailleurs», Le Devoir, 8 mars 1999, p. A7.

+ «De notre provincialisme», Le Devoir, 15 mars 1999, p. A7.

+ «Le Devoir est vendu», Le Devoir, 22 mars 1999, p. A7.

+ «Vous n'étiez donc pas à Paris?», Le Devoir, 29 mars 1999, p. A7.

+ «Regardez-les défiler», Le Devoir, 12 avril 1999, p. A7.

+ «La dame de la rue Panet», Le Devoir, 19 avril 1999, p. A9.

+ "L'émotion est à son comble», Le Devoir, 26 avril 1999, p. A7.

+ «En attendant 2033», Le Devoir, 3 mai 1999, p. A7.

+ «Puisque mon opinion l'intéresse. Un parti politique parlant de soi n'est jamais tellement inventif. Tout est beau, tout est gentil, nous sommes les meilleurs", Le Devoir, 10 mai 1999, p. A7.

+ «Un jeune chien qui mord», Le Devoir, 17 mai 1999, p. A7.

+ «Au septième ciel», Le Devoir, 31 mai 1999, p. A9.

+ «Quand la fierté déménage», Le Devoir, 7 juin 1999, p. A7.

+ «Ā propos du sein qui nous nourrit», Le Devoir, 14 juin 1999, p. A7.

+ "Une nouvelle relève chez les curés», Le Devoir, 21 juin 1999, p. A7.

+ «La modestie des honneurs», Le Devoir, 28 juin 1999, p. A7.

+ «Le retour du chef», Le Devoir, 5 juillet 1999, p. A7.

+ "On a tort d'être malade», Le Devoir, 12 juillet 1999, p. A7.

+ «Fais-moi mal, Jimmy! Jimmy!», Le Devoir, 19 juillet 1999, p. A7.

+ «Vulgaire, dites-vous!», Le Devoir, 26 juillet 1999, p. A7.

+ «As-tu vu ma pub?», Le Devoir, 2 août 1999, p. A7.

+ «Entre Dorval et Dorval», Le Devoir, 9 août 1999, p. A7.

+ «Documents. Les frémissement d'un grand écrivain», Le Devoir, 14 août 1999, p. D3.

+ «Journaliste, ça vous branche?», Le Devoir, 16 août 1999, p. A7.

+ «Ah! si vous aviez connu mon père!», Le Devoir, 23 août 1999, p. A7.

+ «Les nouveaux vieux, c'est pour quand?", Le Devoir, 30 août 1999, p. A7.

+ «Et c'est ainsi que Vialatte est grand», Le Devoir, 4 septembre 1999, p. D5.

+ «De la culture plein les oreilles», Le Devoir, 13 septembre 1999, p. A7.

+ «Le regard vif de la petite dame», Le Devoir, 18 septembre 1999, p. D3.

+ «Té-tu game?», Le Devoir, 20 septembre 1999, p. A7. 
+ «Non, mais quel joli accent!», Le Devoir, 27 septembre 1999, p. A7.

+ «Le temps perdu», Le Devoir, 4 octobre 1999, p. A7.

+ «Les lectures d'un homme de lettres», Le Devoir, 9 octobre 1999, p. D3.

+ «Plus c'est sale...", Le Devoir, 18 octobre 1999, p. A7.

+ «Un rapport angélique», Le Devoir, 23 octobre 1999, p. D7.

+ "Vous êtes pure laine vous?», Le Devoir, 25 octobre 1999, p. A7.

+ "Aveu de compromission", Le Devoir, $1^{\mathrm{er}}$ novembre 1999, p. A9.

+ «Un héros de la langue», Le Devoir, 6 novembre 1999, p. D4.

+ «Mauvais genre», Le Devoir, 8 novembre 1999, p. A9.

+ «Ils en veulent toujours davantage», Le Devoir, 15 novembre 1999, p. A7.

+ «Promenades. Un inquiétant voyage», Le Devoir, 20 novembre 1999, p. D13.

+ «Les prix de la vertu», Le Devoir, 22 novembre 1999, p. A7.

+ «Un certain sourire», Le Devoir, 29 novembre 1999, p. A7.

+ «Portrait de George Sand», Le Devoir, 4 décembre 1999, p. D1.

+ «Un an après », Le Devoir, 6 décembre 1999, p. A7.

+ «Je prends congé», Le Devoir, 13 décembre 1999, p. A7.

\section{TRADUCTION DES ROMANS ET NOUVELLES}

\section{DE GILLES ARCHAMBAULT}

+ One for the Road [Parlons de moi], traduction David Lobdell, Toronto, Oberon Press, 1982, 156 p.

+ The Man with the Flower in his Mouth [La fleur aux dents], traduction de David Lobdell, Toronto, Oberon Press, 1983, 135 p.

+ Standing Flight [La fuite immobile], traduction de David Lobdell, Toronto, Oberon Press, 1986, $110 \mathrm{p}$.

+ In a Minor Key [L'obsédante obèse et autres agressions], traduction de David Lobdell, Toronto, Oberon Press, 1987, 85 p.

\section{PRIX ET DISTINCTIONS}

+ Prix Athanase-David, en 1981, pour l'ensemble de son œuvre.

+ Prix du Gouverneur général, en 1986, pour L'obsédante obèse et autres agressions.

+ Prix Fleury-Mesplet, en 2005, pour sa contribution au progrès de l'édition au Québec.

\section{RÉCEPTION CRITIQUE ET ÉTUDES}

\section{IV.1. Articles de fond et chapitres de livres}

+ CAMBRON, Micheline, «Récit et identité narrative. Fragment, totalisation, apories. Étude des récits de Michel Tremblay et de Gilles Archambault», Québec Studies, vol. 28, 1999/2000, p. 147-159.

+ CAMPION, Blandine, «Parlons de moi de Gilles Archambault. Sous le sceau de la confidence», Études françaises, vol. 35, nº 1, 1999, p. 147-159.

+ CANTIN, Pierre, HARRINGTON, Normand et Paul HUDON, «Gilles Archambault», Bibliographie de la critique de la littérature québécoise dans les revues des XIXe et XXe siècle, t. II, Ottawa, Centre de recherche en civilisation canadienne-française, 1979, p. 165-167.

+ GERBER, Alain, «Présentation critique», ARCHAMBAULT, Gilles, Les pins parasols, Montréal, Les Quinze, 1980, p. 7-10.

+ HÉBERT, François, «Le noir et le blanc, le bleu et le rouge», Études françaises, vol. 11, nº 2 , 1975, p. 111-119. 
+ MARCOTTE, Sophie, «De la mort à la naissance. Un après-midi de septembre de Gilles Archambault», University of Toronto Quarterly, vol. 71, n² 2, 2002, p. 665-673.

+ O'CONNOR, John, "Translations», University of Toronto Quarterly, vol. 50, n 4, 1981, p. 88-89 (aussi «Echoes Reflections», dans Canadian Literature, n 91, 1981, p. 128-131).

+ PELLETIER, Marc, «Une années de consolidation», Livres et auteurs québécois, 1974, p. 14-19.

+ PELLETIER, Marc, "Gilles Archambault: La fuite immobile ou le destin d'un romancier», dans Archives des Lettres canadiennes, t. VIII, Le roman contemporain au Québec, 1960-1985, Fides, 1992, p. 75-92.

+ PLANTE, Raymond, «Ā la recherche des complices absents. Lecture de l'œuvre de Gilles Archambault», Voix et Images du pays, n 9, 1975, p. 209-221.

+ RICARD, François, «La fuite immobile de Gilles Archambault», Liberté, n 93, mai-juin 1974, p. 82-91.

+ RICARD, François, «Trois styles (Archambault, Major, Rivard), Liberté, n 108, novembredécembre 1976, p. 182-192.

+ RICARD, François, «Postface critique», ARCHAMBAULT, Gilles, La fleur aux dents, Montréal, Les Quinze, 1980, p. 243-248.

\section{IV.2. Mémoires et thèses}

+ CAMPION, Blandine, «La faille et le repli. Pour une poétique du récit amoureux chez Gilles Archambault», thèse de doctorat, Montréal, Université de Montréal, 1997, 404 f.

+ CONNOLLY, Carole, "Manifestations du narrataire dans le roman québécois», thèse de doctorat, Ottawa, Université d'Ottawa, 1999, 252 f.

+ HOTTON, Mélanie, «Le récit, entre la mort et le langage. Étude de trois récits québécois contemporains », mémoire de maîtrise, Québec, Université Laval, 2001, 103 f.

\section{IV.3. Entretiens et portraits}

+ Portrait d'écrivains québécois (retranscription d'une entrevue radiophonique, réalisateur Gilbert Picard, animateur Jean Filiatrault), Montréal, radio-document de la Société Radio-Canada, 1980.

+ [s.a.], «Gilles Archambault remporte le Prix David», Le Journal de Montréal, 20 octobre 1981, p. 40.

+ BELLEMARE, Yvon, "Entrevue», suivi de «Des romans à une seule voix», Québec français, no 71, octobre 1988, p. 69-74.

+ BOIVIN, Aurélien, CHAMBERLAND, Roger, GAULIN, André, "Gilles Archambault. Hommage», Québec français, nº 45, 1982, p. 38-39.

+ BRAULT, Jacques, «Gilles Archambault, Prix David 1981 - Hommage», Lettres québécoises, no 24, 1981/1982, p. 67.

+ CAMPION, Blandine, "Gilles Archambault. Sous le signe du doute, écrire», Le Devoir, 14 novembre 1998, p. D9.

+ CAMPION, Blandine, "Gilles Archambault. Écrire au plus près de soi», Spirale, nº 165, marsavril 1999, p. 20-21.

+ CAMPION, Blandine, «Quarante années d'écriture, l'air de rien», Le Devoir, 31 mai 2003, p. F4 et F6.

+ CAYOUETTE, Pierre, "Gilles Archambault. Hanté par le temps», Le Devoir, 16 avril 1994, p. D1-D2.

+ CHABOT, Marc, "Gilles Archambault. Tendresse et discrétion», Nuit blanche, n 66, printemps. 1997, p. 24-26. 
+ DORION, Gilles, «Cette voix que je ne reconnais pas toujours est la mienne», Québec français, $\mathrm{n}^{\circ}$ 71, 1988, p. 74-76.

+ FERLAND, Guy, «La voie intime de Gilles Archambault», Le Devoir, 18 mars 1989, p. D1 et D7.

+ FORTIN, Marie-Claude, «Des écrivains à la chaîne. Le choix de Geneviève Letarte: Gilles Archambault», La Presse, 21 août 2005, cahier «Lectures», p. 2.

+ GODBOUT, Jacques, "Ça sert à quoi, eh?», Le MacLean, vol. 14, nº 7, juillet 1974, p. 11

+ HÉTU, Pierre, "Gilles Archambault: l'indicible et l'intime», Nuit blanche, n 29, octobrenovembre 1987, p. 10-12.

+ LAURIN, Danielle, "Gilles Archambault, diariste déguisé», La Presse, 25 mai 2003, p. F3.

+ LAVOIE, Kathleen, «Gilles Archambault», Le Soleil, 4 novembre 2000, p. D13.

+ MAJOR, André, "Jacques Poulin et Gilles Archambault, à la recherche de la bonne tendresse», Le Devoir, 22 mars 1969, p. 15 (repris dans Québec, mai 1969, p. 124-127).

+ MARCOTTE, Gilles, "Le prix David : un choix au-dessus de tout soupçon», L'Actualité, $1^{\text {er }}$ février 1982, p. 85.

+ MARCOTTE, Gilles, «Le festival Gilles Archambault», L'Actualité, 15 juin 1994, p. 88.

+ MARTEL, Réginald, «Gilles Archambault: J'écris parce que...», La Presse, 20 décembre 1969, p. 21.

+ MARTEL, Réginald, "Gilles Archambault, Prix David: Quand on couronne un honnête homme», La Presse, 24 octobre 1981, p. C2.

+ MARTEL, Réginald, «Dix-sept livres comme autant de miroirs», La Presse, 6 octobre 1991, p. $\mathrm{Cl}$ et $\mathrm{C} 5$.

+ MARTEL, Réginald, «La semaine Archambault», La Presse, 17 avril 1994, p. B3.

+ PARIZEAU, Alice, «Gilles Archambault», La Presse, 23 novembre 1985, p. 17 (repris dans Canadian Literature, no 106, automne 1985, p. 108-110).

+ PAUPARDIN, Dominique, "Les confidences de Gilles Archambault», La Presse, 11 novembre 1995, p. 17 (suppl.).

+ POULIN, Gabrielle, «Le plaisir de la lecture est-il encore possible? Les romans autobiographiques", Le Droit, 28 août 1976, p. 16.

+ RICHER, Anne, "Gilles Archambault. Écrivain pour... conquérir le monde», La Presse, 2 mai 1994, p. A1.

+ ROYER, Jean, «Gilles Archambault, lauréat 1981 du Prix Athanase-David», Le Devoir, 20 octobre 1981, p. 1 (repris dans Canadian Literature, no 91, hiver 1981, p. 128).

+ ROYER, Jean, «Gilles Archambault», Le Devoir, 24 octobre 1981, p. 19.

+ SAINT-PIERRE, G., «Et du haut de Radio-Canada, Gilles Archambault s'écria-t-il: Montréal à nous deux... ? », Le Devoir, 15 février 1964, p. 10.

+ SARFATI, Sonia, "Confidences pour confidences», La Presse, 15 novembre 1997, p. B4.

+ THÉRIAULT, Yves, "Raconter des vies et transmettre des émotions», Les Livres d'ici, 7 février 1979.

+ TREMBLAY, Denis, «Deux lancements, un jour», Montréal-Matin, 11 décembre 1970, p. 19.

+ TREMBLAY, Régis, «Le désespéré distrait, Gilles Archambault Prix David 1981 », Le Soleil, 31 octobre 1981, p. E3.

+ VACHON, George-André, «Chroniques des lettres. Cinq romanciers», Relation, mai 1964, p. 149.

+ VOISARD, Anne-Marie, "Archambault. Écrire pour déjouer la vie qui passe», Le Soleil, 28 mai 1994, p. C7. 


\section{IV.4. Comptes rendus et articles de presse}

\section{IV.4.1. Une suprême discrétion}

+ [Anonyme], «Une suprême discrétion», Bulletin du Cercle juif, vol. 10, n 89, janvier 1964, p. 3.

+ BASILE, Jean, "Une suprême discrétion de Gilles Archambault», Le Devoir, 4 janvier 1964, p. 9.

+ BOUCHER, Ivan, «Une suprême discrétion de Gilles Archambault», Culture, mars 1966, p. 92-93.

+ DAVIAULT, Pierre, "Une suprême discrétion», Livres et auteurs canadiens, 1963, p. 11.

+ DORION, Gilles «Une suprême discrétion», Maurice Lemire (dir.), Dictionnaire des œuvres littéraire du Québec, t. IV, 1960-1969, Montréal, Fides, 1984, p. 921-922.

+ ÉTHIER-BLAIS, Jean, «Une suprême discrétion », University of Toronto Quarterly, vol. 33, n 4 , 1964, p. 515-516.

+ ÉTHIER-BLAIS, Jean, «Livres en français, romans et thêâtre », University of Toronto Quarterly, vol. 33, no 4, 1964, p. 520.

+ L., Michel, «Une suprême discrétion », La Revue de l'Université Laval, vol. 19, nº 4, décembre 1964, p. 304.

+ MAILHOT, Michèle-A., "Une suprême discrétion », Châtelaine, vol. 5, n 4, avril 1964, p. 60.

+ MARCOTTE, Gilles, "Une suprême discrétion de Gilles Archambault», La Presse, 28 décembre 1963, p. 60.

+ McDONALD, Yvan, "Gilles Archambault: Une suprême discrétion», Lectures. Revue mensuelle de bibliographie critique, vol. 10, nº 7, 1964, p. 176.

+ RENAUD, André, "Sur plusieurs titres», Le Droit, 21 mars 1964, p. 11.

+ VACHON, André, «Une suprême discrétion », Relations, n 281, mai 1964, p. 149.

\section{IV.4.2. La vie à trois}

+ [Anonyme], «La vie à trois», Bulletin du Cercle juif, vol. 11, n 104, juin-juillet 1965, p. 3.

+ BLAIS, Lise, "La vie à trois», Châtelaine, vol. 6, n 5, mai 1965, p. 78.

+ BOIVIN, Aurélien, «La vie à trois», Maurice Lemire (dir.), Dictionnaire des œuvres littéraires du Québec, t. IV, 1960-1969, Montréal, Fides, 1984, p. 947-948.

+ CHALOIN, Solange, «Flirter avec un prix littéraire: un jeu passionnant mais épuisant», Le Devoir, 7 novembre 1964, p. 17.

+ GIGNAC, Rodrigue, «La vie à trois», Le Soleil, $1^{\mathrm{er}}$ mai 1965, p. 8.

+ JASMIN, Claude, «La fuite de Gilles Archambault», L'Actualité, mars 1975, p. 6 et 11.

+ MARCOTTE, Gilles, "La vie à trois par Gilles Archambault», La Presse, 20 mars 1965, p. 6 (suppl.).

+ MELANÇON, André, "Archambault (Gilles), La vie à trois », Lectures, mai 1965, p. 246-247.

+ TÉTU, Michel, «La vie à trois», Livres et auteurs canadiens, 1965, p. 64.

\section{IV.4.3. Le tendre matin}

+ [Anonyme], «Le tendre matin », Le Québec en bref, vol. 3, nos 5-6, mai-juin 1969, p. 30.

+ ANDRĖS, Bernard, "Le tendre matin», Maurice Lemire (dir.), Dictionnaire des œuvres littéraires du Québec, t. IV, 1960-1969, Montréal, Fides, 1984, p. 864-865.

+ ÉTHIER-BLAIS, Jean, "Avant l'aventure solitaire de la vie», Le Devoir, 14 juin 1969, p. 12.

+ GAY, Paul, «Le tendre matin», Le Droit, 12 avril 1969, p. 8.

+ MAJOR, André, «Ã la recherche de la bonne tendresse», Le Devoir, 22 mars 1969, p. 15.

+ MAJOR, André, "Le tendre matin», Québec 69, mai 1969, p. 126-127.

+ MARTEL, Réginald, «Un voyage déprimant qui s'appelle la vie», La Presse, 29 mars 1969, p. 23.

+ POULIN, Gabrielle, «Gilles Archambault: Le tendre matin», Relations, juillet-août 1970, p. 222. 
+ ROBIDOUX, Réjean, «Livres en français. Romans, récits, nouvelles, contes», University of Toronto Quarterly, vol. 39, n 4, 1970, p. 440.

+ ROUX, Paul, «Un romancier à la recherche d'un style», Le Soleil, 22 mars 1969, p. 36.

+ SAINT-ONGE, Paule, "Le tendre matin», Châtelaine, vol. 10, n 6, juin 1969, p. 46.

+ THÉBERGE, Jean-Yves, «Le tendre matin d'un jour gris», Le Canada français, 23 avril 1969, p. 40.

+ THÉRIO, Adrien, «Le tendre matin», Livres et auteurs québécois, 1969, p. 21.

\section{IV.4.4. Parlons de moi}

+ [Anonyme], "Parlons de moi», Le Livre canadien, vol. 2, n 91, 1971, p. [?].

+ BEAULIEU, Invanhoé, «Gilles Archambault. Ce roman est-il déjà dépassé ? », Le Soleil, 16 janvier 1971. p. 41.

+ BERGENS, Andrée, "Parlons de moi de Gilles Archambault. Fascinant et exaspérant», Le Droit, 7 juin 1980, p. 19.

+ BOURBONNAIS, Nicole, «Parlons de moi», Maurice Lemire (dir.), Dictionnaire des œuvres littéraires du Québec, t. V, 1970-1975, Montréal, Fides, 1987, p. 651-652.

+ BROUSSEAU, Paul, «Qu'est-ce qui fait pleurer les civilisés?», La Presse, 20 mars 1971, p. D2.

+ DANSEREAU, Estelle, «One for the Road», Quarry, été 1984, p. 90.

+ DE LABSADE, Françoise, "Parlons de moi», Livres et auteurs québécois, 1970, p. 45.

+ EMPLETON, Wayne, «Highlights of an Ignoble Life», The Vancouver Sun, 26 novembre 1982, p. L28.

+ ÉTHIER-BLAIS, Jean, «Tristesse et fantaisie», Le Devoir, 9 janvier 1971, p. 11.

+ KING, Deirdre, "One for the Road», Quill and Quire, octobre 1982, p. 31-32.

+ PELLERIN, Gilles, «Parlons de moi», Livres et auteurs québécois, 1980, p. 18.

+ ROBIDOUX, Réjean, "Romans, récits, nouvelles, contes», University of Toronto Quarterly, vol. 40, no 4, 1971, p. 424-432.

+ SUTHERLAND, Robert, "Quebec Books», The Globe and Mail, 30 octobre 1982, p. E14.

+ THÉBERGE, Jean-Yves, "Un triste sire ou un pauvre bougre. Parlons de moi», Le Canada français, 24 février 1971, p. 42.

\section{IV.4.5. La fleur aux dents}

+ [Anonyme], "La fleur aux dents», Le Livre canadien, vol. 4, n 38, 1973, p. [?].

+ ANDRÈS, Bernard, «La fleur aux dents», Maurice Lemire (dir.), Dictionnaire des œuvres littéraires du Québec, t. V, 1970-1975, Montréal, Fides, 1987, p. 342-343.

+ DUHAMEL, Roger, "Une passion d'hier et une passion d'aujourd'hui», Le Droit, 2 janvier 1971, p. 7.

+ DUSSEAULT, Serge, "Porté au cinéma, que sera le roman d'Archambault?», La Presse, 7 décembre 1974, p. E15.

+ ÉTHIER-BLAIS, Jean, «Talent et défis de M. Gilles Archambault», Le Devoir, 6 mai 1972, p. 15.

+ FITZGERALD, Judith, "The Exuberance of the French Writer", The Globe and Mail, 3 mars 1984, p. E19.

+ HANDOCK, Geoff, «Eternal Optimist an Engaging Hero in Quebec», The Sunday Sun, 18 décembre 1983, p. E21.

+ HENCHIRI, Michèle, «La fleur aux dents», Livres et auteurs québécois, 1971, p. 62-63.

+ MINNI, Dino, "Mediocre déjà vu, The Man with the Flower in his Mouth», The Vancouver Sun, 25 février 1984, p. D10.

+ PIAZZA, François, «La fleur aux dents», Montréal-Matin, 16 janvier 1972, p. 17. 
+ THÉBERGE, Jean-Yves, «La fleur aux dents», Le Canada français, 19 janvier 1972, p. 46.

+ THÉRIEN, Gilles, «La fleur aux dents. Un vrai film pour la télévision », Voix et Images, vol. 1, no 2, 1975, p. 295-301.

+ VERDIER, Nathalie, "La fleur aux dents», Le Droit, 25 mars 1972, p. 15.

+ WAXMAN, Martin, "The Man with the Flower in his Mouth», Quill and Quire, avril 1984, p. 34.

\section{IV.4.6. Enfances lointaines}

+ [Anonyme], «Enfances lointaines», Le Livre Canadien, vol. 3, n 243, 1972, p. [?].

+ ANDRĖS, Bernard, «Enfances lointaines», Maurice Lemire (dir.), Dictionnaire des œuvres littéraires du Québec, t. V, 1970-1975, Montréal, Fides, 1987, p. 296-297.

+ CHARLAND, Jean-Paul, "Enfances lointaines», Le Médecin du Québec, vol. 8, no 1, janvier 1973, p. 80.

+ DAVIAU, Monique-Diane, «Enfances lointaines », Lettres québécoises, n 66, été 1992, p. 21-23.

+ MARTEL, Réginald, "C'était hier et c'est peut-être demain», La Presse, 8 mars 1992, p. C3.

+ TETU, Michel, «Enfances lointaines», Livres et auteurs québécois, 1972, p. 55.

\section{IV.4.7. La fuite immobile}

+ ADACHI, Ken, "Quebec Fiction», The Toronto Star, 10 août 1986, p. A9.

+ BONNENFANT, Joseph, «La fuite immobile», Livres et auteurs québécois, 1974, p. 56-57 (aussi Maurice Lemire (dir.), Dictionnaire des œuvres littéraire du Québec, t. V, 1970-1975, Montréal, Fides, 1987, p. 360-361).

+ ÉTHIER-BLAIS, Jean, «Vocation d'écrire et d'aimer chez Gilles Archambault», Le Devoir, 6 avril 1974, p. 20.

+ JASMIN, Claude, "Deux romans opposés. Gilles Archambault et Andrée Maillet», L'Actualité, février 1975, p. 7.

+ LEMIEUX, Jean, «La fuite immobile de Gilles Archambault», Le Canada français, 19 juin 1974, p. 57.

+ MARTEL, Réginald, «Pourquoi vivre? Comment vivre?», La Presse, 30 mars 1974, p. D3.

+ PIAZZA, François, «La voix au chapitre», Montréal-Matin, 24 mars 1974, p. 23.

+ PONTAUT, Alain, «En toutes lettres. Archambault et La fuite immobile. De l'incertitude à la maîtrise», Le Jour, 2 mars 1974, p. 18.

+ POULIN, Gabrielle et DIONNE, René, «Romans, récits, nouvelles, contes», University of Toronto Quarterly, vol. 44, n 4, 1975, p. 318.

+ THÉRIAULT, Jacques, «Le dernier né de Gilles Archambault. Une vision "intimiste" d'une enfance lointaine», Le Devoir, 18 mars 1974, p. 10.

+ TREMBLAY, Robert, «La fuite immobile ou l'imagination stagnante», Le Soleil, 27 avril 1974, p. 39.

\section{IV.4.8. Le tricycle}

+ GOBIN, Pierre B., "Le tricycle... », Livres et auteurs québécois, 1974, p. 165 (aussi Maurice Lemire (dir.), Dictionnaire des œuvres littéraires du Québec, t. V, 1970-1975, Montréal, Fides, 1987, p. 888-889).

\section{IV.4.9 Les pins parasols}

+ BASILE, Jean, «Vient de paraître. Les pins parasols», Le Jour, 7 mai 1976, p. 23 (aussi «Un nouveau roman de Gilles Archambault; une médiation poétique et les ouvriers », dans Le Devoir, 15 mai 1976, p. 12). 
+ BEAUDOIN, Réjean, «Sous Les pins parasols de Gilles Archambault», Les Livres d'íci, n 42, 1976, p. 14.

+ BOURBONNAIS, Nicole, "Gilles Archambault, Les pins parasols», Livres et auteurs québécois, 1976, p. 57-60.

+ JASMIN, Claude, "A pour Archambault, G pour Grignon», L'Actualité, mai 1976, p. 46.

+ MARTEL, Réginald, «L'absurdité apprivoisée», La Presse, 10 avril 1976, p. D2.

+ MORENCY, Jean, "Les pins parasols», Gilles Dorion (dir.), Dictionnaire des œuvres littéraires du Québec, t. VI, 1976-1980, Montréal, Fides, 1994, p. 637-638.

+ POULIN, Gabrielle, «Romans, récits, nouvelles, contes », University of Toronto Quarterly, vol. 46, n 4, été 1977, p. 363.

+ POULIN, Gabrielle, «Les pins parasols de Gilles Archambault. Hors de la famille, point de salut», Le Droit, 29 mai 1979, p. 17.

+ ROYER, Jean, «Les pins parasols. Puisque la vie est un rêve», Le Soleil, 17 juillet 1976, p. C5.

+ THÉBERGE, Jean-Yves, «Seul ou avec d'autres. Retrouver son enfance ou chercher le bonheur», Le Canada français, 2 juin 1976, p. 48.

\section{IV.4.10. Stupeurs et Les plaisirs de la mélancolie}

+ BEAULIEU, Michel, «Ah! Les fruits du plaisir!», Le Livre d'ici, 7 mai 1980, p.12.

+ CAYOUETTE, Pierre, «Gilles Archambault. Hanté par le temps», Le Devoir, 16 avril 1994, p. D1$\mathrm{D} 2$.

+ DIONNE, René, «Le moraliste, le témoin et l'intime. Les plaisirs de la mélancolie de Gilles Archambault», Lettres québécoises, nº 19, automne 1980, p. 61-63.

+ DORION, Gilles, «Stupeurs» et «Les plaisirs de la mélancolie», Gilles Dorion (dir.), Dictionnaire des œuvres littéraires du Québec, t. VI, 1976-1980, Montréal, Fides, 1994, p. 768-770.

+ MARTEL, Réginald, «Le sentier du plaisir», La Presse, 21 avril 1979, p. D3.

+ MARTEL, Réginald, «Une nostalgie d'aujourd'hui», La Presse, $1^{\mathrm{er}}$ mars 1980, p. D3.

+ OUELLETTE-MiCHALSKA, Madeleine, "À l'écart des modes», Le Devoir, 5 avril 1980, p. 21.

+ ROYER, Jean, "D'un plaisir à l'autre dans l'intimité des mots», Le Devoir, 28 avril 1979, p. 21.

+ ROYER, Jean, «Gilles Archambault. Les plaisirs de la mélancolie», Le Devoir, 31 mai 1980, p. 1718 (aussi dans Livres et auteurs québécois, 1981, p. 247-248).

+ THÉRIO, Adrien, "À retenir pour vos lectures», Lettres québécoises, n 16, hiver 1979-1980, p. 72.

+ TOUPIN, Gilles, «Les stupéfactions de Gilles Archambault», La Presse, 27 février 1994, p. B6.

\section{IV.4.11. Le voyageur distrait}

+ FERRON, Jacques, "Gilles Archambault. Un voyageur distrait et dépossédé», Les Livres d'ici, 11 novembre 1981, p. 1 (aussi dans Nos Livres, vol. 13, n 50, février 1982, p. 3 ; Québec français, nº 45, mars 1982, p. 38-39; Lettres québécoises, n² 25, printemps 1982, p. 21-22).

+ LAPIERRE, René, "Le voyageur distrait», Livres et auteurs québécois, 1981, p. 19-21 (aussi dans Liberté, no 139, janvier-février 1982, p. 97-98).

+ MAILHOT, Michèle, "Le voyageur distrait», Le Droit, 26 juin 1982, p. 14.

+ MARTEL, Réginald, «Un voyageur distrait. À travers l'impasse de la vie», La Presse, 31 octobre 1981, p. D2.

+ PELLETIER, Mario, «Le voyageur distrait, le meilleur Archambault», Le Devoir, 4 novembre 1981, p. 23.

+ THÉRIO, Adrien, «S'interroger sur l'existence», Lettres québécoises, nº 52, hiver 1988, p. 61. 
+ TREMBLAY, Régis, «Le désespéré distrait. Gilles Archambault, prix David 1981 », Le Soleil, 31 octobre 1981, p. E3.

+ VANASSE, André, «L'âge de la tendresse. Le voyageur distrait», Lettres québécoises, n 25 , printemps 1982, p. 597-599.

+ VANASSE, André, «De la marginalité», Voix et Images, vol. 7, n 3, 1982, p. 597-599.

\section{IV.4.12. $\bar{A}$ voix basse}

+ BASILE, Jean, «Gilles Archambault», Le Devoir, 5 janvier 1982, p. 8.

+ DE LAMIRANDE, Claire, "La vie est triste hélas et j'ai entendu tous les disques», Le Droit, 5 novembre 1983, p. 34.

+ POULIN, Gabrielle, «Mourir à voix basse», Lettres québécoises, n 32, hiver 1983/1984, p. 21-22.

+ MARTEL, Réginald, «Les spires de l'œuvre en rond», La Presse, $1^{\mathrm{er}}$ octobre 1983, p. D3.

+ ROY, Monique, "Écrire À voix basse», Le Devoir, 22 octobre 1983, p. 19 (aussi dans Spirale, n 39, décembre 1983, p. 2 ; Nos livres, vol. 14, n 50, février 1983, p. 21 ; Canadian Literature, no 86, printemps 1983, p. 147; Lettres québécoises, n 32, 1983/1984, p. 21-22).

+ THÉORET, France, «À voix basse», Spirale, n 39, décembre 1983, p. 2.

+ TREMBLAY, Régis, "Le discours essentiel de Gilles Archambault», Le Soleil, 24 mars 1984, p. C5.

\section{IV.4.13. Le regard oblique}

+ MELANÇON, Benoît, «Le regard oblique», Spirale, n 46, octobre 1984, p. 3.

+ QUESNEL, Pierre, «L'humour charmant d'un égoïste impertinent», Le Devoir, 14 juillet 1984, p. 19 (aussi dans Les Livres d'ici, juin-juillet-août 1984, p. 9; Canadian Literature, nº 101, été 1984, p. 102-103).

\section{IV.4.14. L'obsédante obèse et autres agressions}

+ BOIVIN, Jean-Roch, «Gilles Archambault et l'art de la sourdine», Le Devoir, 20 juin 1987, p. D3.

+ CHASSAY, Jean-François, «Excellent millésime», Spirale, nº 72, septembre 1987, p. 21.

+ KOUSTAS, Jane, «In Minor Key», University of Toronto Quarterly, vol. 62, nº 1, 1992, p. 110111.

+ MARTEL, Réginald, «La vie, l'écriture, l'amour, la mort, des aventure dérisoires», La Presse, 15 juin 1987, p. E3.

+ THÉRIAULT, Marie José, «Un livre pour tester la conscience», Lettres québécoises, no 4 , automne 1987, p. 30.

\section{IV.4.15. Chroniques matinales}

+ MELANÇON, Benoît, "Recueils et restes», Spirale, no 88, mai 1989, p. 10-11.

+ GRIMALDI, Francine, «Chroniques matinales», La Presse, 25 janvier 1989, p. B4.

+ MAJOR, Robert, «Papiers collés, papiers à lire», Voix et Images, vol. 14, n 3, 1989, p. 498-503.

\section{IV.4.16. Les choses d'un jour}

+ BEAUDOIN, Réjean, «Ironiser en catimini ou persifler en chœur », Liberté, n 202, août 1992, p. 118-125.

+ CORNELLIER, Louis, «L'actualité de Gilles Archambault», Le Devoir, 7 mars 1992, p. D3. 
+ GUAY, Hervé, «Les illusions perdues de Gilles Archambault», Le Devoir, 12 octobre 1991, p. D3.

+ MARTEL, Réginald, "Quand l'écrivain prête sa parole intime au poète....», La Presse,

13 octobre 1991, p. D3.

\section{IV.4.17. Un après-midi de septembre}

+ [s.a.], «Qu'est-ce que le destin? Décider de fouiller les origines, c'est risquer d'aller au cœur des choses", Lettres québécoises, automne 1993, p. 21-22.

+ BORDELEAU, Francine, "Confession secrète», Le Devoir, 24 avril 1993, p. D3.

+ FORTIN, Marie-Claude, "Gilles Archambault. L'écrit de la mémoire», Voir, vol. 7, nº 21, 22 avril 1993, p. 25.

+ GIRARD, Marie-Claire, «Enfance noyée», Le Devoir, 24 avril 1993, p. D1-D2.

+ MARCOTTE, Gilles, «Récit de la mort d'une mère», L'Actualité, $1^{\text {er }}$ août 1993, p. 83.

+ MARTEL, Réginald, "La vie après septembre», La Presse, 18 avril 1993, p. B4.

+ THÉRIO, Adrien, «Un après-midi de septembre», Lettres québécoises, n 71, automne 1993, p. 21-22.

\section{IV.4.18. Tu ne me dis jamais que je suis belle}

+ ALLARD, Jacques, "Quand la prose se fait belle», Le Devoir, 18 juin 1994, p. D5

+ BERTIN, Raymond, «Tu ne me dis jamais que je suis belle», Voir, vol. 8, n 23, 5 mai 1994, p. 13.

+ POULIN, Andrée, «L'angoisse incarnée», Le Droit, 14 mai 1994, p. A8.

\section{IV.4.19. Un homme plein d'enfance}

+ BERTIN, Raymond, «Amour défeintes. Un homme plein d'enfance», Voir, vol. 10, n 36, 5 septembre 1996, p. 31.

+ CAMPION, Blandine, «Un hymne à l'amour sur arrière-fond de désespoir. Un homme plein d'enfance de Gilles Archambault», Spirale, n 152, janvier-février 1997, p. 24.

+ GÉRIN, Marie-Ėve, "Hymne à la fragilité. Un homme plein d'enfance», Le Soleil, 22 septembre 1996, p. B9.

+ MARCOTTE, Hélène, «Un homme plein d'enfance», University of Toronto Quarterly, vol. 67, $\mathrm{n}^{\circ}$ 1, 1997/1998, p. 350.

+ MARTEL, Réginald, "Archambault. La perfection de son art», La Presse, 8 septembre 1996, p. B3.

+ TRUDEL, Clément, "Gilles Archambault. Vivre sereinement sur un volcan », Le Devoir, 15 septembre 1996, p. D1-D2.

\section{IV.4.20. Dernières chroniques matinales}

+ LEDUC, Louise, «L'observateur», Le Devoir, 15 juin 1996, p. D4.

\section{IV.4.21. Les maladresses du cœur}

+ CAMPION, Blandine, "L'œuvre d'une vie. Une esthétique réussie de l'échec », Le Devoir, 24 octobre 1998, p. D4.

+ KARCH, Pierre, "Les maladresses du cœur», University of Toronto Quarterly, vol. 69, nº 1 , 1999/2000, p. 359-371.

+ LACHANCE, Lise, «Le drame d'une écrivain tari», Le Soleil, 22 septembre 1996, p. B10.

+ MARTEL, Réginald, «Une élégance toute classique», La Presse, 18 octobre 1998, p. B4. 


\section{IV.4.22. Courir à sa perte}

+ BIRON, Michel, «Le plaisir d'être second», Voix et Images, vol. 26, n² 2, 2001, p. 401-405.

+ CAMPION, Blandine, «13, chemin des vieilles connaissances. Courir à sa perte de Gilles Archambault», Spirale, nº 176, janvier-février 2001, p.3.

+ CHARTRAND, Robert, «Les brouillages de l'autoportrait», Le Devoir, 16 septembre 2000, p. D3.

+ LABRECQUE, Marie, "Courir à sa perte», Voir, vol. 14, no 42, 19 octobre 2000, p. 36.

+ LAVOIE, Kathleen, «"Plus je vieillis, plus je trouve la vie belle". Gilles Archambault», Le Droit, 11 novembre 2000, p. A36.

+ MARCOTTE, Gilles, «Vadeboncœur et Archambault, fidèles à eux-mêmes», L'Actualité, $1^{\text {er }}$ décembre 2000, p. 119.

+ MARTEL, Réginald, «Proche de la perfection», La Presse, 17 septembre 2000, p. C3.

\section{IV.4.23. Comme une panthère noire}

+ CHARTRAND, Robert, "Petite musique au crépuscule», Le Devoir, 3 novembre 2001, p. D5.

+ LABRECQUE, Marie, "Comme une panthère noire», Voir, 15, n 46, 15 novembre 2001, p. 45.

+ MARTEL, Réginald, «La vie s'en va doucement», La Presse, 21 octobre 2001, p. B3.

+ VIGNEAULT, Benny, "Quand se profile la nuit. Gilles Archambault sonde le plus profond des âmes dans Comme une panthère noire», Le Soleil, 11 novembre 2001, p. B5.

\section{IV.4.24. De si douces dérives}

+ BIRON, Michel, «La riche surface des choses», Voix et Images, vol. 29, n 1, 2003, p. 137-141.

+ CAMPION, Blandine, «Douceur trompeuse», Le Devoir, 31 mai 2003, p. F1.

+ MARCOTTE, Gilles, «Manuel de survie», L'Actualité, 15 septembre 2003, p. 91.

\section{IV.4.25. De l'autre côté du pont}

+ BIRON, Michel, «L'extrême fixité des choses qui passent», Voix et Images, vol. 30, n 3, 2005, p. 153-159.

+ FORTIN, Marie-Claude, «Deux belles voix d'ici», La Presse, 30 janvier 2005, cahier «Lectures», p. 10.

+ LABRECQUE, Marie, "Un nouveau départ», Le Devoir, 13 novembre 2004, p. F6.

+ LESSARD, Valérie, "Gilles Archambault persiste et signe», Le Droit, 6 novembre 2004, p. A8. 